\title{
Енергоощадний режим роботи ректифікаційної колони зневоднення етиленгліколю
}

\begin{abstract}
Проведено теоретичний аналіз можливості використання в ректифікаційній колоні зневоднення етиленгліколю кількох потоків теплоносія з різними температурами для зменшення витрат на енергоносії при виробництві етиленгліколю. Літературний огляд сучасних досліджень проведено за напрямами: оптимізаџія при проектуванні та експлуатації ректифікаційної колони, зменшення енерговитрат при ректифікації $i$ методи оцінки енергоефективності прочесу ректифікації. Метою статті є аналіз ефективності модернізаціі ректифікаційної колони для зменшення витрат на енергоносії при виробництві етиленгліколю за рахунок використання теплоносіїв різних температурних потенціалів. Для оцінки економіі енергоресурсів використано модель, де колона забезпечується тепловою енергією, яку отримано від теплового насосу. Запропонована модель теплообміну в ректифікаційній колоні враховує внутрішній конвективний теплообмін між дефлегматором і кубовим залишком та зовнішній теплообмін, який реалізується тепловим насосом. Тепловий насос у моделі працює за ідеальним ичиклом Карно, споживає механічну енергію і переносить теплову енергію від дефлегматора до кубового залишку, збільшуючи температурний потенціал, при цьому коефіцієнт перетворення роботи в теплоту залежить від температурного перепаду між джерелом теплоти (дефлегматором) та споживачем (кип'ятильник ректифікачійної колони). Сформульовано та обтрунтовано припущення для розв'язання моделі, наведено приклад розрахунку енергоефективності процесу ректифікації бінарної сумімі етиленгліколю з водою, отримано залежність енергоефективності від температури альтернативного потоку теплоносія. Зроблено висновок про наявність екстремуму теоретичної відносної економії витрат на енергоресурси в колоні зневоднення етиленгліколю від температури другого потоку теплоносія.
\end{abstract}

Ключові слова: ректифікація; етиленгліколь; зневоднення.

Постановка проблеми. В технології отримання етиленгліколю на основі гідратації оксиду етилену основними споживачами теплової енергії $є$ випарні апарати та ректифікаційна колона. В технологічній схемі [1] встановлено атмосферну ректифікаційну колону для розділення бінарної суміші гліколю 3 водою від 0,8 до 0,995 масової частки гліколю в суміші. Перепад температури в колоні становить близько 100 град. С, температура у парогенераторі кубового залишку становить близько 200 град. С, підвід теплоти з таким потенціалом обумовлений типовою конструкцією ректифікаційної колони, де теплота підводиться виключно до кубового залишку і відводиться у дефлегматорі, а температурний перепад у колоні забезпечено холодним зрошенням після дефлегматора.

Пропонується провести оцінку можливості використання теплоносія 3 різним температурним потенціалом для зменшення витрат на енергоносії при виробництві етиленгліколю.

Аналіз попередніх досліджень. Літературний огляд сучасних досліджень проведено за напрямками: оптимізація при проектуванні та експлуатації ректифікаційної колони, зменшення енерговитрат при ректифікації, і методи оцінки енергоефективності процесу ректифікації.

Відомі методики розрахунку [2] теплового балансу ректифікаційної колони передбачають розрахунок кількості холодного зрошення з приблизним розподілом теплового навантаження між тарілками.

При моделюванні в універсальній моделювальній програмі ChemCad ректифікаційної установки для розділення бінарної суміші більшість авторів [3-7] також використовує загальний тепловий баланс верхньої та нижньої частин колони з початковими умовами холодного зрошення.

Для зменшення енерговитрат на ректифікацію у колонах, що працюють під тиском, вхідну суміш підігрівають до стану потоку рідини 3 парою (STREAM), наприклад, автори оригінального енергоощадного проекту [8] використовують двофазну умову подачі суміші для розділення вуглеводневого розчинника та води.

У колонах фракційного розділення при відборі фракцій використовується підігрів рідкої фази по висоті колони або підігрів парової фази за рахунок ії стискання між секціями колони [9]. 
Теоретична оцінка енергоефективності процесу ректифікації ускладнена широким вибором параметрів процесу, серед яких основні - це продуктивність та чистота кінцевого продукту. Для оцінки енергоефективності ректифікації пропонується критерій [10], який враховує термодинамічний коефіцієнт корисної дії ректифікаційної колони та температурний потенціал теплоносіїв. Ректифікаційна колона розглядається як тепловий двигун для розділення суміші, використовуються фундаментальні закони термодинаміки.

Невирішена частина наукової проблеми - сформулювати модель переносу теплової енергії у ректифікаційній колоні з використанням теплоносіїв різних температурних потенціалів.

Метою цієї статті $\epsilon$ аналіз впровадження енергоощадного режиму роботи ректифікаційної колони 3 використанням теплоносіїв різних температурних потенціалів на прикладі процесу зневоднення етиленгліколю, зокрема, отримання теоретичних показників для двох теплоносіїв та встановлення впливу температури другого теплоносія на теоретичну економію витрат на енергоресурси i максимального ефекту впровадження енергоощадного режиму.

Викладення основного матеріалу. Схема модернізації ректифікаційної колони зневоднення етиленгліколю (рис. 1) передбачає використання теплоносіїв різних температурних потенціалів. Моделі теплообміну в традиційній та модернізованій схемах наведено на рисунку 2. Матеріальний баланс колони:

$$
\left\{\begin{array}{l}
F=P+W \\
F X_{\mathrm{F}}=P X_{P}+W X_{W}
\end{array},\right.
$$

де $F$ - масова витрата суміші етиленгліколю з водою, яка подається для розділення до ректифікаційної колони, кг/с; $P$ - масова витрата дистиляту, що відбирається з ректифікаційної колони, кг/с; $W$ - масова витрата кубового залишку, що відбирається з ректифікаційної колони, кг/с; $X_{F}$ - масова частка цільового компоненту (води) у вхідній суміші, частка; $X_{P}$ - масова частка цільового компоненту у дистиляті, що відбирається з ректифікаційної колони, частка; $X_{W}$ - масова частка цільового компоненту у кубовому залишку, що відбирається з ректифікаційної колони, частка.

Тепловий баланс ректифікаційної колони до модернізації, Вт:

$$
F i_{\mathrm{F}}+Q_{\mathrm{W} 1}=P i_{\mathrm{P}}+W i_{\mathrm{W}}+\mathrm{Q}_{\mathrm{COOL}},
$$

де $i_{\mathrm{F}}$ - питома ентальпія вхідної суміші, Дж/кг; $i_{\mathrm{P}}-$ питома ентальпія дистиляту, Дж/кг; $i_{\mathrm{W}}-$ питома ентальпія кубового залишку, Дж/кг.

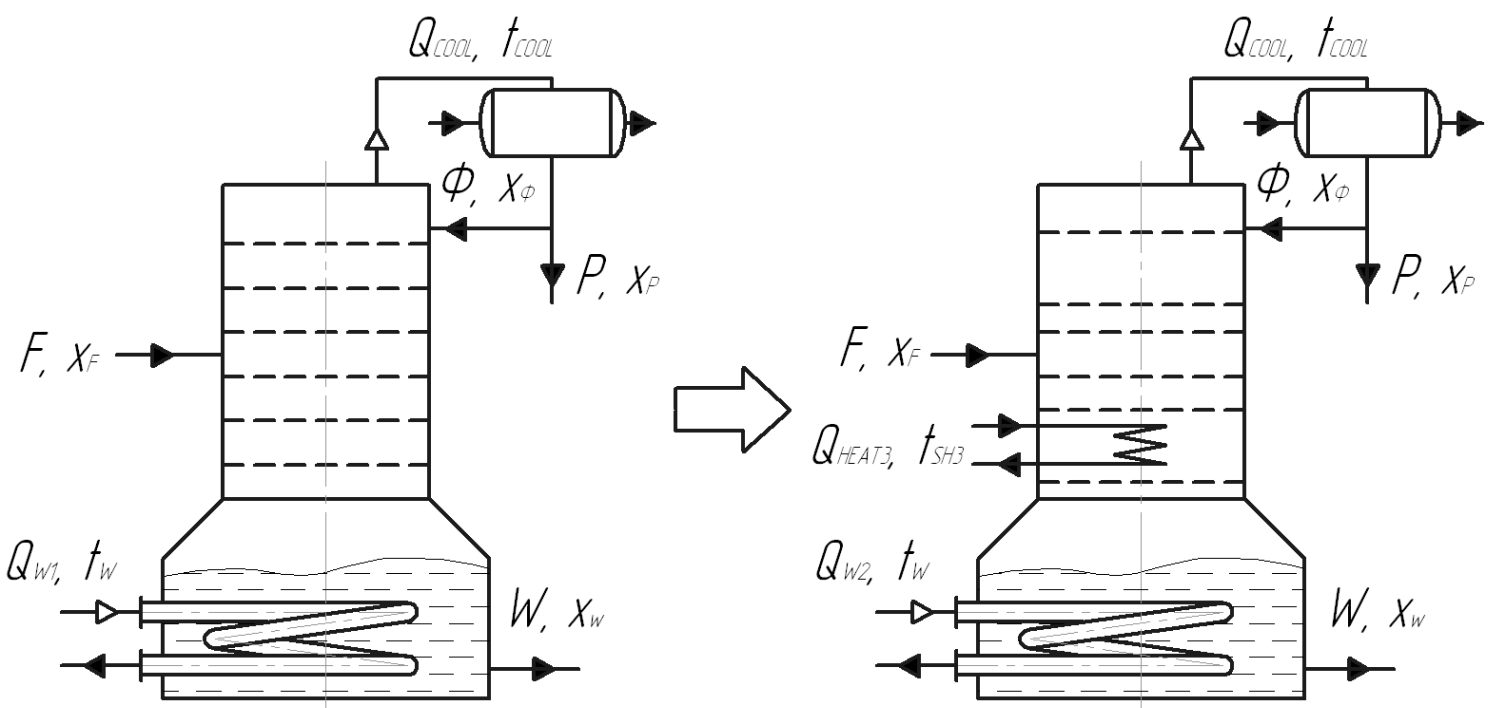

Рис. 1. Модернізація ректифікаційної колони

Тепловий баланс ректифікаційної колони після модернізації, Вт:

$$
F i_{\mathrm{F}}+Q_{\mathrm{W} 2}+Q_{\mathrm{HEAT} 3}=P i_{\mathrm{P}}+W i_{\mathrm{W}}+\mathrm{Q}_{\mathrm{COOL}} \quad \Rightarrow \quad Q_{\mathrm{W} 1}=Q_{\mathrm{W} 2}+Q_{\mathrm{HEAT} 3} .
$$

Таким чином, питомі енерговитрати на процес ректифікації після запропонованої модернізації не змінились, але частина теплоти, що підводиться ( $\left.Q_{H E A T 3}\right)$, має менший температурний потенціал. 


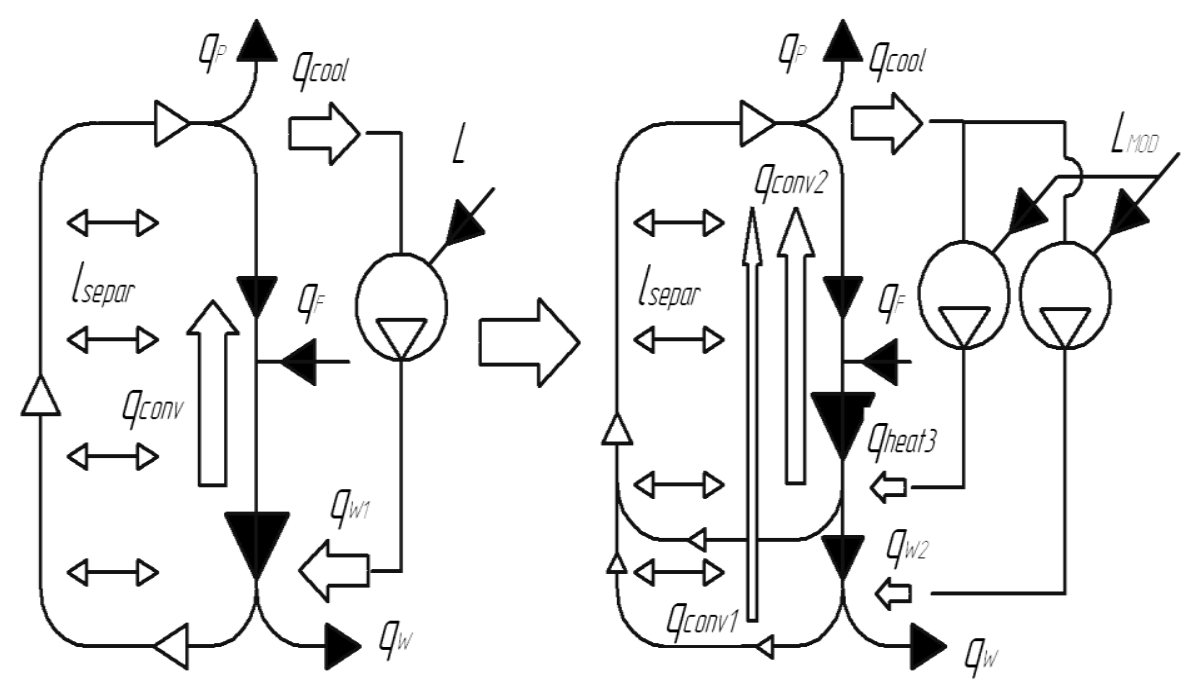

Рис. 2. Рух теплоти та маси в традииійній та модернізованій схемах ректифікації

Для оцінки економії енергоресурсів використаємо модель, де колона забезпечується тепловою енергією, що отримано від теплового насосу, який працює за циклом Карно. Витрати механічної енергії на процес ректифікації до модернізації, Вт:

$$
L=\frac{Q_{\mathrm{W} 1}}{\varepsilon}=Q_{\mathrm{w} 1} \frac{T_{W}-T_{C O O L}}{T_{C O O L}},
$$

де $\varepsilon$ - коефіцієнт перетворення роботи в теплоту.

Витрати механічної енергії на процес ректифікації після модернізації, Вт:

$$
L_{\mathrm{MOD}}=\frac{Q_{W 2}}{\varepsilon_{1}}+\frac{Q_{H E A T 3}}{\varepsilon_{2}}=Q_{\mathrm{W} 2} \frac{T_{C O O L}}{T_{W 2}-T_{C O O L}}+Q_{\mathrm{HEAT} 3} \frac{T_{C O O L}}{T_{S H 3}-T_{C O O L}} .
$$

Відносна економія витрат на енергоресурси складає, \%:

$$
\eta=\left|\frac{L-L_{M O D}}{L}\right| \cdot 100 \% \text {. }
$$

Приклад розрахунку проведено для процесу ректифікації бінарної суміші етиленгліколю (компонент В) з водою (компонент А) та масових концентрацій $\mathrm{X}_{\mathrm{W}}=0,001 ; \mathrm{X}_{\mathrm{F}}=0,8 ; \mathrm{X}_{\mathrm{P}}=0,999$, флегмове число дорівнює один.

Розрахункову схему наведено на рисунку 3.

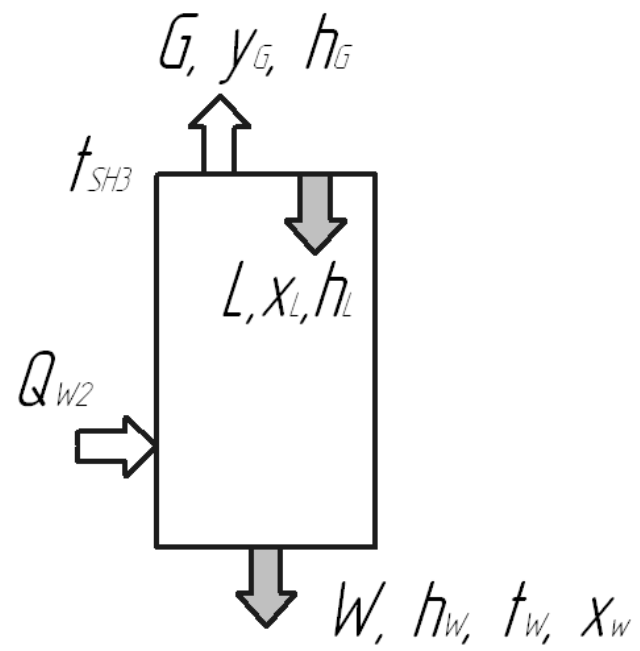

Рис. 3. Розрахункова схема для визначення температури другого теплоносія 


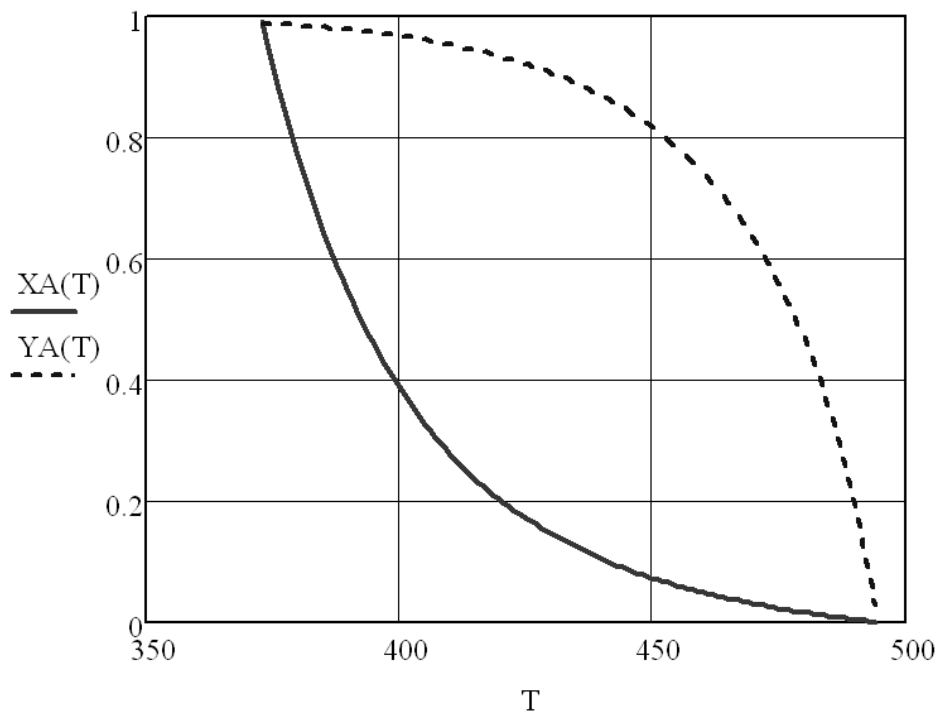

Рис. 4. Рівноважні мольні частки компонента «А» (води) у рідкій та паровій фазах бінарної суміші етиленгліколь-вода залежно від температури

Прийнято такі припущення: тиск у колоні по висоті однаковий - $10^{5}$ Па, витрати у навколишнє середовище відсутні, температурна залежність тиску насиченої пари над рідиною відповідає закономірності $\ln (P)=\frac{A}{T}+B$, температури рідини і пари при однаковому значенні поточної висоти колони рівні, тепловий ефект розчинення етиленгліколю у воді зневажливо малий, тиск парів над бінарною рідиною відповідає закону Дальтона. Результати розрахунків у програмі Mathcad наведено на рисунках 4-5.

Висновки. Запропоновано нову методику оцінки енергоефективності процесу ректифікації при використанні теплоносіїв з різним температурним потенціалом, відносна теоретична економія витрат на енергоресурси в колоні зневоднення етиленгліколю склала 37 \%.

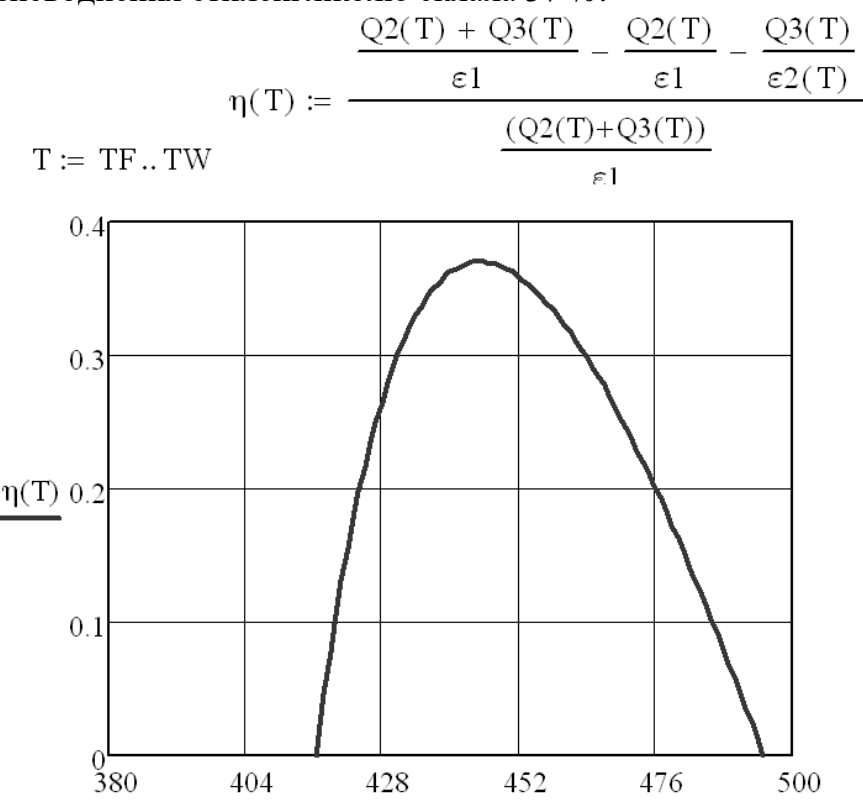

Рис. 5. Відносна економія витрат на енергоресурси при порівнянні традиційноі та модернізованої схем ректифікаиії, частка

Перспективи подальших досліджень. Спрямування подальших досліджень полягає у практичному впровадженні результатів роботи, створенні математичної моделі процесу та перевірці їі адекватності.

Список використаної літератури:

1. Дымент О.Н. Гликоли и другие производные окисей этилена и пропилена / О.Н. Дымент, К.С. Казанский, А.М. Мирошников. - М. : Химия, 1976. -372 с. 
2. Кузнецов А.А. Расчеты процессов и аппаратов нефтеперерабатывающей промышленности / А.А. Кузнецов, С.М. Кагерманов, Е.И. Судаков. - изд. 2-е, пер. и доп. - Л. : Химия, 1974

3. Huzova I.O. Modeljuvannja ta optymizacija roboty rektyfikacijnoji kolony dlja otrymannja $97 \%$ propilenu / I.O. Huzova // Himija, tehnolohija rechovyn ta jih zastosuvannja. - CTAS, 2018. - Vyp. 1, № 2, P. 111-118 [Електронний ресурс]. - Режим доступу : http://science.lpnu.ua/sites/default/files/journalpaper/2018/dec/15280/181935verstka2.pdf.

4. Поджарський М.A. Теоретичні основи процесів перегонки й ректифікації : конспект лекцій / М.А. Поджарський. - Д. : РВВ ДНУ, 2006. - 24 с.

5. Dynamic modeling and simulation of crude fractionation column with three side strippers using Aspen HYSYS Dynamics: A best practice for crude distillation column dynamic modeling / N.Parthiban, N.Nagarajan, V.K. Mahendra, K.D. Senthil // Journal of Petroleum and Gas exploration Research. - 2013. - № 3. - P. 31-39.

6. Семикин К.B. Оптимизация режимных параметров колонны К-2 установки первичной переработки нефти / K.В. Семикин // Известия Санкт-Петербургского государственного технологического ин-та (технического ун-та). - 2013. - № 19. - С. 78-79.

7. Wills A. On Gradient-Based Search for Multivariable System Estimates / A.Wills, B.Ninness // IEEE Transactions on Automatic Control. - 2008. - № 1. - P. 298-306.

8. Soun Ho Lee Optimize Design for Distillation Feed / Soun Ho Lee, Michael J. Binkley. - USA, Houston, Texas : GTC Technology, 2019 [Електронний ресурс]. - Режим доступу : https://www.gtctech.com/optimize-designfor-distillation-feed/.

9. Anton A. Kiss A review on process intensification in internally heat-integrated distillation columns / Anton A. Kiss, Žarko Olujić // Chemical Engineering and Processing: Process Intensification. -December 2014. - Vol. 86. - P. 125-144. [Електронний ресурс]. - Режим доступу : https://doi.org/10.1016/j.cep.2014.10.017.

10. Quick assessment of binary distillation efficiency using a heat engine perspective / M.Blahušiak, A.A. Kiss, S.RA. Kersten, B.Schuur // Energy. - 1 December 2016. - Vol. 116, Part 1. - P. 20-31 [Електронний ресурс]. - Режим доступу : https://doi.org/10.1016/j.energy.2016.09.097.

\section{References:}

1. Dyment, O.N., Kazanskij, K.S. and Miroshnikov, A.M. (1976), Glikoli i drugie proizvodnye okisej jetilena $i$ propilena, Himija, M., 372 p.

2. Kuznecov, A.A., Kagermanov, S.M. and Sudakov, E.I. (1974), Raschety processov $i$ apparatov neftepererabatyvajushhej promyshlennosti, izd. 2-e, per. i dop., Himija, L.

3. Huz'ova, I.O. (2018), «Modeljuvannja ta optymizacija roboty rektyfikacijnoji kolony dlja otrymannja $97 \%$ propilenu», Himija, tehnolohija rechovyn ta jih zastosuvannja, CTAS, Issue 1, No. 2, pp. 111-118, [Online], available at: http://science.lpnu.ua/sites/default/files/journal-paper/2018/dec/15280/181935verstka2.pdf

4. Podžars'kyj, M.A. (2006), Teoretyčni osnovy procesiv perehonky j rektyfikaciji, Konspekt lekcij, RVV DNU, D., 24 p.

5. Parthiban, N., Nagarajan, N., Mahendra, V.K. Senthil, K.D. (2013), «Dynamic modeling and simulation of crude fractionation column with three side strippers using Aspen HYSYS Dynamics: A best practice for crude distillation column dynamic modeling», Journal of Petroleum and Gas exploration Research, No. 3, pp. 31-39.

6. Semikin, K.V. (2013), «Optimizacija rezhimnyh parametrov kolonny K-2 ustanovki pervichnoj pererabotki nefti», Izvestija Sankt-Peterburgskogo gosudarstvennogo tehnologicheskogo in-ta (tehnicheskogo un-ta), No. 19, pp. 78-79.

7. Wills, A. Ninness, B. (2008), «On Gradient-Based Search for Multivariable System Estimates», IEEE Transactions on Automatic Control, No. 1, pp. 298-306.

8. Lee, Soun Ho and Binkley, Michael J. (2019), Optimize Design for Distillation Feed, GTC Technology, USA, Houston, Texas, [Online], available at: available at: https://www.gtctech.com/optimize-design-for-distillation-feed/

9. Kiss, Anton A. and Olujić, Žarko (2014), «A review on process intensification in internally heat-integrated distillation columns», Chemical Engineering and Processing: Process Intensification, Vol. 86, pp. 125-144, [Online], available at: https://doi.org/10.1016/j.cep.2014.10.017

10. Blahušiak, M., Kiss, A.A., Kersten, S.RA, and Schuur, B. (2016), «Quick assessment of binary distillation efficiency using a heat engine perspective», Energy, Vol. 116, Part 1, pp 20-31, [Online], available at: https://doi.org/10.1016/j.energy.2016.09.097

Двойнос Ярослав Григорович - старший викладач кафедри машин та апаратів хімічних i нафтопереробних виробництв, кандидат технічних наук Національного технічного університету України «Київський політехнічний інститут імені Ігоря Сікорського», м. Київ.

E-mail: 0507293553@ukr.net.

Король Антон Юрійович - магістр Національного технічного університету України «Київський політехнічний інститут імені Ігоря Сікорського», м. Київ.

E-mail: korol4753@gmail.com.

Подиман Григорій Сергійович - аспірант Національного технічного університету України «Київський політехнічний інститут імені Ігоря Сікорського», м. Київ.

E-mail: podiman_g_s@ukr.net. 